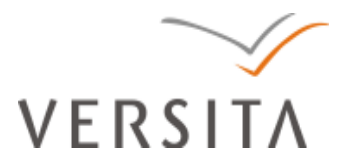

Folia Oeconomica Stetinensia

DOI: 10.2478/v10031-010-0013-7

\title{
ustWIIEL
}

Wydzial Nauk Ekonomicznych i Zarządzania Uniwersytetu Szczecińskiego

\section{APPLYING A NEW BUBBLE TEST FOR A COMPOSITE INDICATOR*}

Dieter Gerdesmeier, Prof.

European Central Bank

Kaiserstrasse 29, 60311 Frankfurt am Main, Germany

emai:dieter.gerdesmeier@ecb.europa.eu

Hans-Eggert Reimers, Prof.

Hochschule Wismar

Postfach 1210, 23952 Wismar

email:Hans-Eggert.Reimers@hs-wismar.de

Barbara Roffia, Ph.D.

European Central Bank

Kaiserstrasse 29, 60311 Frankfurt am Main, Germany

emai: barbara.roffia@ecb.europa.eu

Received 9 March 2011, Accepted 30 May 2011

\begin{abstract}
The paper applies a new bubble test checking the explosiveness of asset prices, especially real stock prices, real house prices and a combination of these prices. In this study, a sample of 17 OECD industrialised countries and the euro area over the period 1969 Q1 - 2010 Q2 is investigated. The authors carry out recursive unit root to determine the beginning and the end of a period of bubble behaviour. The new test procedure finds evidence for rejecting the non-bubble hypothesis. Particularly the composite indicator includes hints of bubble situations before the actual financial crisis.
\end{abstract}

Keywords: bubbles, explosive unit root test.

JEL classification: E37, E44.

* The paper does not necessarily reflect the views of either the European Central Bank or the Frankfurt School of Finance and Management or the Hochschule Wismar. 


\section{Introduction}

Economists often use the expression "bubble" to describe an asset price that is not in line with the level justified by economic fundamentals ${ }^{1}$. As a matter of fact, several dramatic rises in stock prices seem to have occurred throughout history in various countries and periods and have accordingly been described as bubbles. This study applies some empirical tests attempting to identify these bubbles in asset price market in a number of industrialized countries.

There exist a large number of papers trying to detect "rational" bubbles. For instance, equity prices contain a rational bubble if investors are paying more for the stock than the value they know would be justified on the basis of the value of the discounted dividend payments. This happens because investors expect to be able to sell the stocks at a higher price in the future. The pricing of the stock is still rational, and there are no arbitrage opportunities. The model is derived from a utility maximization problem ${ }^{2}$.

Testing for bubbles is essentially testing the validity of the traditional stock market valuation model. Most approaches follow the approach of Diba and Grossman ${ }^{3}$, who propose the use of unit root and cointegration tests for stock prices and observable fundamentals. These procedures are applied in the analysis of Gerdesmeier, Reimers and Roffia ${ }^{4}$. They use the cross country sample of important OECD members and the period of about three decades. They carry out univariate and multivariate panel tests to find evidence of bubbles in the stock market. Univariate tests clearly reject the non-bubble hypothesis pointing towards the fact that there have been for some countries and sometimes over protracted periods from the path implied by the fundamentals. However, the results based on cointegration tests provide clear evidence against the existence of a bubble. In contrast, a more recent approach applies unit root test procedures to find mildly explosive unit roots as a hint for bubbles 5 .

This paper is structured as follows: Section 2 starts by reviewing some theoretical issues related to stock market valuation and bubbles identification; Section 3 proceeds by discussing the data underlying the empirical part, while Section 4 reports the results of the empirical analysis. In particular, the latter focuses on tests for the evidence of bubbles in some OECD countries in a univariate and multivariate context. Section 5 draws some conclusions. 


\section{Literature Review}

\subsection{Stock prices and their determinants: some general considerations}

For the stock market to fulfil its economic functions sufficiently, equity prices must not deviate systematically from their 'fundamental' value. This value usually depends on the future stream of income that firms are expected to generate. If equity prices fully reflect all the available information that is relevant for valuing stocks, they are said to meet the efficiency condition $^{6}$. If the latter condition is not met, stock prices might convey the wrong signals to market participants about the true profitability and risks of certain companies or even of the stock market as a whole, thus leading to an inefficient allocation of capital in the economy.

In order to determine such a fundamental value, an approach to value stocks would have to be derived and possible sources of market inefficiencies would need to be developed. On a general basis, financial assets are valued according to the discounted present value of the future cash flow that investors expect to derive from holding the asset. The discount rates applied to future cash flows are the expected rates of return that investors demand for holding the asset in their portfolios. Applied to the theory of the valuation of shares, the discounted cash flow method corresponds to the dividend discount model ${ }^{7}$.

If stock prices are efficient, they will equal the discounted present value of (rationally) expected future dividends. In this context, the discount rates can be broken down into a measure of "opportunity costs" (which are the returns expected on investing in assets other than stocks), and a corresponding equity-specific risk premium, which is in essence related to the degree of riskiness of an asset as perceived by investors. As stocks are widely seen to be riskier than, for example, government bonds or bank deposits, investors demand a correspondingly higher expected rate of return for holding stocks. In fact, the results in the empirical literature generally support the view of a positive equity (risk) premium, the latter being for instance approximated by the long-term average of the margins between the observed returns on stocks and the one on either long-term bonds or short-term bank deposits ${ }^{8}$.

The main conclusion drawn from the dividend discount model is that stock prices are by their very nature forward-looking. If it is further assumed that current stock prices embody all relevant information available to the investors, what follows is that changes in stock prices are mainly driven by "news", i.e. by incoming information that leads market participants to revise their expectations about stock fundamentals.

As regards the identification of possible sources of stock market 'inefficiency', the fact that stock price fundamentals are not directly observable implies that any assessment of whether 
stocks are efficiently priced requires a judgement as to whether investors' expectations about future dividends, interest rates and stock market risks are justifiable and correctly reflected in stock prices. In general, such an assessment can be based on both empirical and theoretical arguments.

From a theoretical perspective, the hypothesis of market efficiency rests on the assumption that investors have an incentive to make use of all available information when deciding at which price to sell or buy stocks. Even if investors do not all use the available information in a rational way, it can be assumed that an effective arbitrage mechanism is at work and ensures that rational investors push securities prices sufficiently close to their fundamental values ${ }^{9}$.

This arbitrage mechanism would generally work in a way that rational investors would sell (or sell short) an "overpriced" security in one market and simultaneously buy the same asset or a security with the same pay-off structure as a hedge in another market where it is correctly priced or "underpriced". As a consequence, the prices on the two different markets can be expected to balance out quickly at the fundamentally justified level. In the real world, however, arbitrage activities might not be as powerful as just described, due, for instance, to the fact that perfect substitutes for stocks are usually not available and that arbitrageurs might be confronted with borrowing constraints and short-term investment horizons.

However, limited arbitrage per se is by no means sufficient to create market inefficiencies. It has to be compounded by some form of irrational behaviour on the part of at least some investors (investor sentiment). Theories of 'investor sentiment' - based on evidence from experimental studies and psychological theories about belief formation - try to explain the motives behind investors behaving in a way that drives prices away from fundamentals. Most of them can be subsumed under 'overreaction' and 'positive feedback trading'. Overreaction refers to the situation where, after a series of positive earnings news, investors become overly optimistic about future earnings announcements and dividend expectations, thus driving stock prices up to excessively high levels. Instead, positive feedback investors buy stocks after prices rise with the expectation that observed price increases will continue, with the result that stock prices may in fact increase further on account of higher demand, thus giving rise to further expectations of future price rises ${ }^{10}$.

These theories lead to another distinction regarding the source of a possible bubble. On the one hand, a bubble could emerge from overreacting investors ('intrinsic bubbles') ${ }^{11}$, while on the other hand, bubbles could result from positive feedback trading, whereby selffulfilling expectations must be seen as the main driving force behind a bubble that feeds itself once triggered by some extraneous event ('extrinsic bubbles') ${ }^{12}$. Taken together, imperfections 
in real-world capital markets, combined with the potential threat of irrationality on the part of some investors, imply that the efficiency of stock prices remains an empirical question. However, the empirical evidence with regard to the efficiency of stock prices remains at best ambiguous, varying according to the selected theoretical framework and the applied empirical methodology. As the fundamental value of stocks is not directly observable, it is impossible to decide with certainty whether stocks are efficiently priced at a specific point in time or not. A commonly used tool to assess the level of stock prices is to put stock valuation ratios, such as the dividend yield and price-earnings ratio, in a historical context. This is based on the idea that these valuation ratios should, over time, eventually revert to some long-run equilibrium level. Statistically, historical comparisons can be carried out in two ways. A simple method consists of comparing current valuation ratios with historical averages. Alternatively, a long-run equilibrium relationship between stock market valuation ratios and, for example, real interest rates and potential output growth (as a rough measure of long-term dividend growth) can be estimated, allowing the long-run equilibrium to vary over time. For both methods a stock market over- or undervaluation might be indicated when current valuation ratios are considerably out of line with the estimated long-run equilibrium level.

It should be kept in mind that, however, neither of the two approaches can provide a sufficient proof of a stock market bubble. Hence, historical comparisons cannot solve the problem of diagnosing bubbles with an adequate degree of certainty. They can only provide some weak indications of periodic market excesses pushing valuation ratios far beyond thresholds set by historical patterns.

\subsection{Theoretical and model-based considerations on detecting asset price bubbles}

Attempts to identify an asset price bubble in real time have a long-standing tradition in economics and econometrics. While recent studies have mostly focused on the (purely) statistical criterion of the deviation of an asset price indicator exceeding a certain threshold when compared to an underlying development (such as, for instance, a one-sided trend or filter), it has become evident that several possibilities of defining an asset prices bubble and its burst remain which differ according either to the indicator used (such as, for instance, stock price index, house price index or a composite indicator of the two) or to the threshold beyond which an asset price development can be defined as being "excessive". However, the definition and/or detection of asset price bubbles have also been discussed in the literature on the basis of more theoretical grounds. For instance, in his paper, Filardo ${ }^{13}$ defines an asset price bubble a situation in which "an asset price tends to grow persistently out of line with fundamentals, often in 
a frothy way, and tends to end unexpectedly with a sharp correction". He also mentions that an asset price could be related to situations of persistent undervaluations and overvaluations. Therefore, in his view the analysis should focus on a bubble's size, and in particular an asset price bubble should be huge enough to affect macroeconomic variables which are relevant for monetary policy decisions. This definition is in line with Kindleberger ${ }^{14}$, who stated that "a bubble is an upward price movement over an extended range that then implodes". Shiller ${ }^{15}$ gives a more precise definition, according to which "a speculative bubble [is] a situation in which news of price increases spur investor enthusiasm, which spreads by psychological contagion from person to person, in the process amplifying stories that might justify the price increases and bringing in a larger and larger class of investors, who, despite doubts about the real value of an investment, are drawn to its partly through envy of others' successes and partly through a gambler's excitement". This definition has a strong psychological basis which is relevant for Shiller to explain speculative bubbles. Simon ${ }^{16}$ instead states that "a bubble is an asset market event where prices rise, potentially with justification, rise further on the back of speculation, and then fall dramatically for no clear reason when the speculation collapses". At least, Brunnermeier ${ }^{17}$ defines bubbles as episodes when asset prices exceed an asset's fundamental value due to the fact that current owners believe that they can resell the asset at an even higher price in the future, whereas Grantham ${ }^{18}$ states that bubbles are definable events when the prices exceed a threshold marked by a two standard deviations away from a long-term trend.

Froot and Obstfeld ${ }^{19}$ suggest a model for the stock prices, fundamental prices and bubble process, which is represented by the following:

$$
\begin{gathered}
P_{t}=\left(\frac{1}{1+r}\right) E_{t}\left(D_{t}+P_{t+1}\right) \\
P_{t}^{P V}=\sum_{j=1}^{\infty}\left(\frac{1}{1+r}\right)^{j} E_{t}\left(D_{t+j}\right) \\
B_{t}=\left(\frac{1}{1+r}\right) E_{t}\left(B_{t+1}\right) \\
P_{t}=P_{t}^{P V}+B_{t}
\end{gathered}
$$

It is apparent that the asset price contains two components, a "fundamental" component $\left(P_{t}^{P V}\right)$ and a "bubble" component $\left(B_{t}\right)$. Without a bubble the asset price equals its fundamental value. Under bubble conditions the asset price may show an explosive behaviour inherent in $\left(B_{t}\right)$. This explosive property is very different from a random walk behaviour and is base of the testing strategy of Phillips and $\mathrm{Yu}^{20}$ to date bubbles. 
The testing strategy of Phillips and $\mathrm{Yu}^{21}$ bases on a test procedure having power to discriminate between unit root behaviour in a process and mildly explosive stochastic alternatives. It relies on recursively calculated right-sided unit root tests to assess evidence for the alternative. In particular, they apply standard unit root tests with usual unit root asymptotics under the null against the alternative of an explosive or mildly explosive root. Therefore, the following autoregressive specification is estimated by recursive least squares:

$$
X_{t}=\mu+\delta X_{t-1}+\varepsilon_{t}, \quad \varepsilon_{t} \sim \text { iid }\left(0, \sigma^{2}\right)
$$

allowing for the fact that the iid assumption may be relaxed with the usual adjustments of the tests. The null hypothesis is $H_{0}: \delta=1$ and the right-tailed alternative hypothesis is $H_{1}: \delta>1$, which allows for mildly explosive autoregressions with $\delta=1+c / k_{n}$, where $k_{n} \rightarrow \infty$ and $k_{n} / n \rightarrow 0$. The Dickey-Fuller $t$-statistic is the $t$-statistic of the OLS estimate of $\delta$. If the model (5) is the data generating process for all $t$, then a right-sided unit root test could test a unit root null against an explosive alternative. However, market can correct its prices and bubbles seem to collapse. Therefore, unit root tests had little power in detecting periodically collapsing bubbles. To overcome this drawback Phillips and $\mathrm{Yu}^{22}$ suggest to use the supremum of recursively determined Dickey-Fuller $t$-statistics. Here is the aim to determine the timeline of the bubble behaviour, which needs forward recursive regressions. The beginning of the bubble is estimated as the first date when the Dickey-Fuller $t$-statistics is greater than its corresponding critical value of the right-sided unit root test. If a bubble starts, the end of the bubble will be determined as the first period when the Dickey-Fuller $t$-statistic is below aforementioned critical value. Phillips and $\mathrm{Yu}^{23}$ show that consistent estimation of start and end point requires a slow divergence rate of critical values. For practical implementation they suggest to use the $1 \%$ critical values of the Dickey-Fuller $t$-statistic.

\section{The data set}

The present study analyses the properties of composite indicator compromised the stock prices (represented by the share prices indices) and the house prices. The change of composite asset price indicator has been calculated by combining the stock price index with the house price index as follows ${ }^{24}$ :

$$
\Delta C=\phi_{1} * \Delta \text { Stock prices }+\phi_{2} * \Delta \text { House prices }
$$

where $\phi_{1}$ is normalised to 1 and $\phi_{2}=\sigma_{\Delta \mathrm{SP}} / \sigma_{\Delta \mathrm{HP}}$ (that is the ratio of the standard deviation of the two variables). The weight is calculated recursively throughout the sample period ${ }^{25}$. The quarterly 
changes are cumulated to calculate the composite level variable. The main sources of the series are the BIS, DataStream, Euro area wide model (AWM), the European Central Bank (both official and internal databases), Eurostat, Global Financial Data, IMF International Financial Statistics, the respective National Central Banks for each country, OECD Main Economic Indicators and Economic Outlook and Reuters. A detailed description of the series used in the analysis is contained in a more recent work analysing the role of money and credit for asset price misalignments ${ }^{26}$.

The dataset used for the analysis consists of quarterly data collected for 17 main industrial economies (plus the euro area as a whole) and spans over more than three decades, starting in 1969 Q1 and ending in 2010 Q2 ${ }^{27}$. The countries considered in the sample set are the following: Australia (AU), Canada (CA), Denmark (DK), the euro area (EA), France (FR), Germany (DE), Ireland (IE), Italy (IT), Japan (JP), the Netherlands (NL), New Zealand (NZ), Norway (NO), Portugal (PT), Spain (ES), Sweden (SE), Switzerland (CH), the United Kingdom (UK) and the United States (US). In the following section we focus on testing for the evidence of a bubble in these countries on the basis of univariate analyses.

The data is shown in Figure 1. Most countries exhibit a long lasting increase. There is one peak in the series mostly in the last 10 years. At the end these series show a remarkable decrease. The exceptions of this development are Germany and Japan which have a peak in nineties and afterwards a long period of price reductions.

\section{Testing for the evidence of bubbles}

The starting point of this test is represented by eq. (5). The explosive root is tested using the unit root test of $\mathrm{Ng}$ and Perron ${ }^{28}$. The critical values are determined by MacKinnon ${ }^{29}$. They vary depending on the sample size and the deterministic specification of the test equation. The test specification used allows for an intercept. The critical values are given in Table 1.

The bubble test is applied to the real stock price, real house price and the composite indcator. The test is recursively conducted. The first test period covers 1969 Q1 : 1989 Q1 and the unit root test statistic in determined. In the next step the sample size is extended by one quarter and again the unit root test statistic is calculated. This is repeated until the last quarter (2010 Q2) is included. The results of the unit root test statistics are given in Figure 2. The blue (red and green) lines show the results of the composite indicator (equity stock prices and house prices, respectively). For example, the t-statistic of the stock market is lower than zero for Australia whereas the $t$-statistics of the house price are lower than zero until 1995. 
Lateron the $t$-statistics increase. In $2001 \mathrm{Q} 1$ the null hypothesis of unit root is rejected against the alternative of an explosive root. The warning against a bubble remains until 2010 (see also Table 2). Moreover, Table 2 presents the periods, when the test statistics exceeds the critical values given in Table 1.

Table 1. Critical values of the bubble test

\begin{tabular}{|c|c|}
\hline Sample size & Critical value \\
\hline 80 & .639 \\
\hline 90 & .635 \\
\hline 100 & .632 \\
\hline 110 & .630 \\
\hline 120 & .628 \\
\hline 130 & .627 \\
\hline 140 & .625 \\
\hline 150 & .624 \\
\hline 160 & .623 \\
\hline 170 & .622 \\
\hline
\end{tabular}

Source: MacKinnon (1996).

In the beginning it is worth noting that there is no indication of a bubble behaviour for three countries (Germany, Spain and New Zealand). Looking at the real stock prices in three countries (Sweden, Japan and the euro area) short bubble periods are indicated. The results will change, if the real house price market is considered. In nine countries there are bubble periods. In some countries these periods are short, for example in Denmark, France and Switzerland less than five quarters. Following the Phillips and $\mathrm{Yu}^{30}$ who suggest that the span should be longer than $\log (n)$ (n equals the sample size) these cases are not be denoted as a bubble period. In contrast, in other countries these periods are remarkable long, for example in Australia, Ireland and United Kingdom for more than 20 quarters. It is worth to note that the explosive price movement indication started in 1997 Q3 in Ireland. It ended in 2007 Q3. Turning to the composite indicator the null of a unit root against an explosive root could rejected in 11 countries. In some countries only one period is founded, whereas in the euro area there are three episodes. Moreover, in seven of eleven countries the last period of bubble indication is in 2007 or 2008. Only for the two countries (namely Canada and Australia) there are indications of a bubble in the most recent period 2010 Q2. 


\section{Australia}

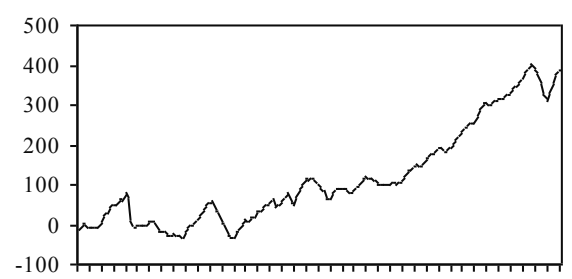

197019751980198519901995200020052010

\section{Canada}

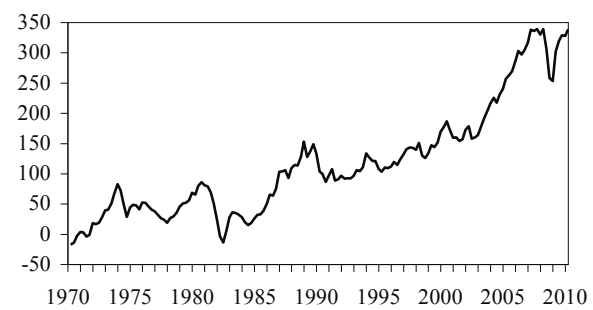

\section{Switzerland}

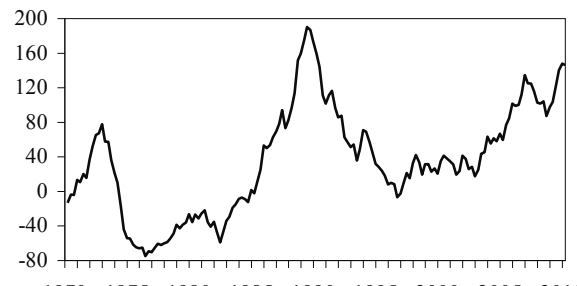

$\begin{array}{lllllllll}1970 & 1975 & 1980 & 1985 & 1990 & 1995 & 2000 & 2005 & 2010\end{array}$
Germany

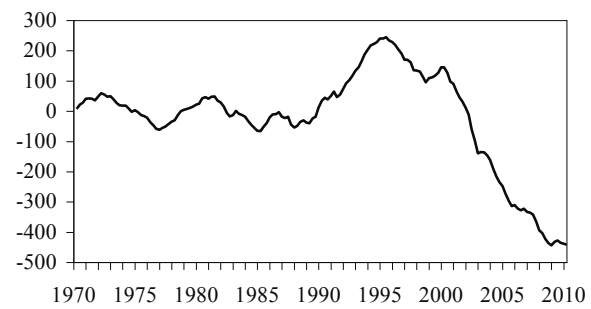

Spain

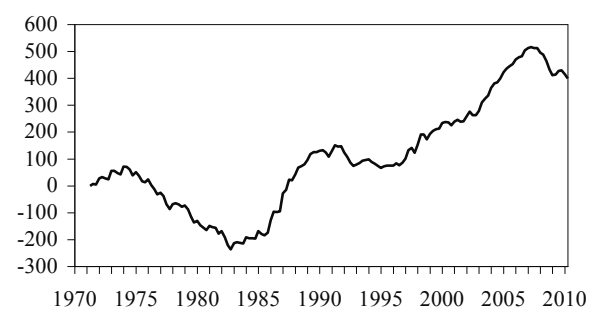

Ireland

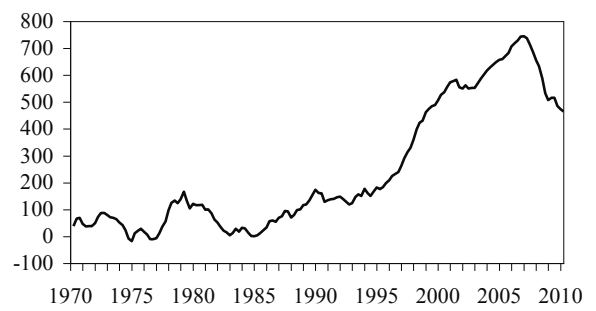

Japan

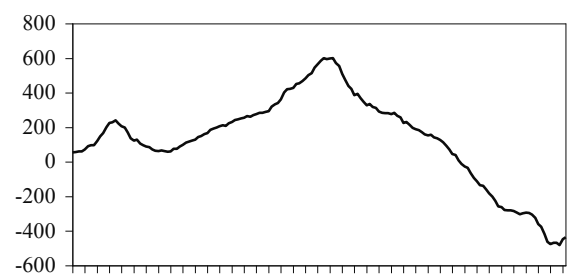

$\begin{array}{lllllllll}1970 & 1975 & 1980 & 1985 & 1990 & 1995 & 2000 & 2005 & 2010\end{array}$ 
Netherlands

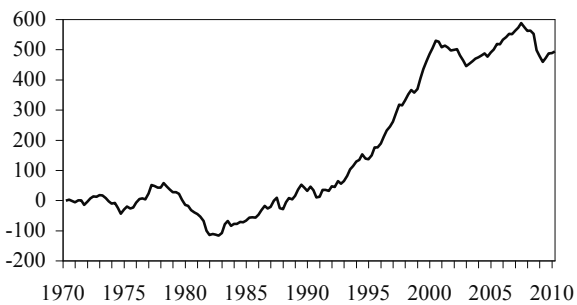

\section{Norway}

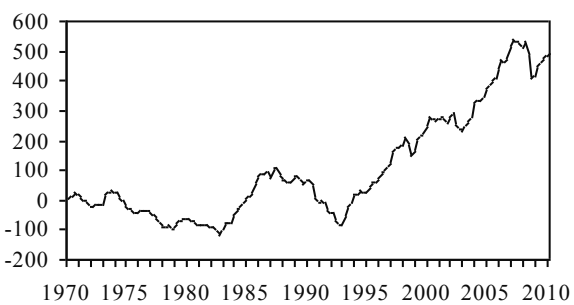

Portugal

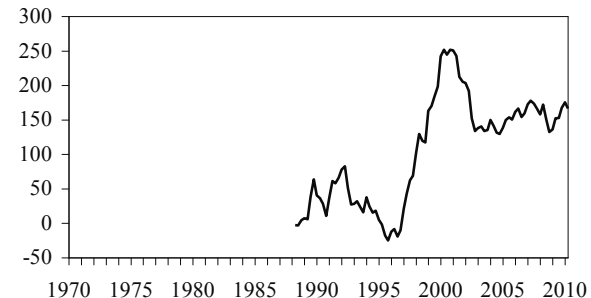

Euro area

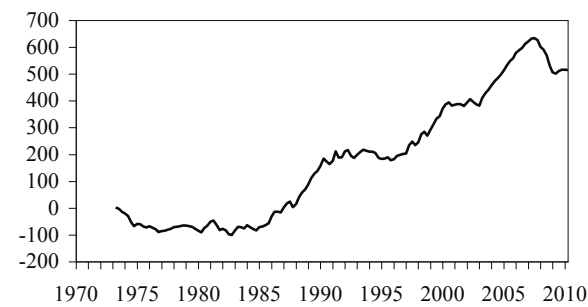

United States

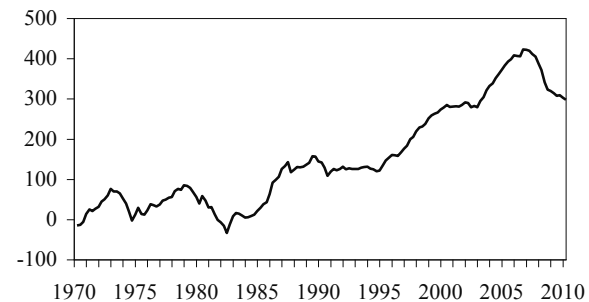

Fig. 1. Composite indicator of equity and house market

Source: own research. 
Australia

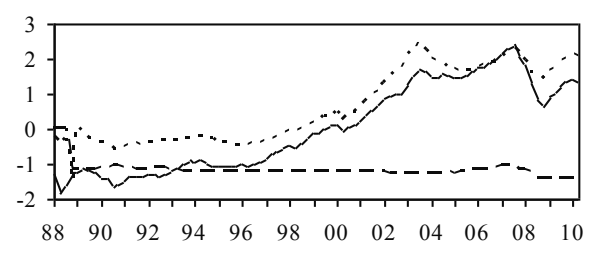

-T_COM_AU... T. T_H_AU $_{-}---\mathrm{T}_{-} \mathrm{STO} \mathrm{T}_{-} \mathrm{AU}$
Canada

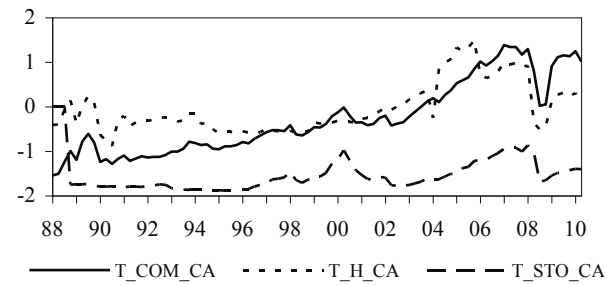

Switzerland

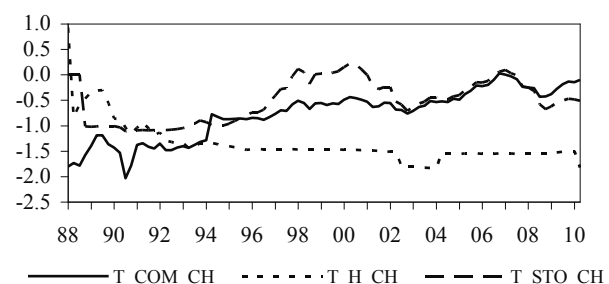

Denmark

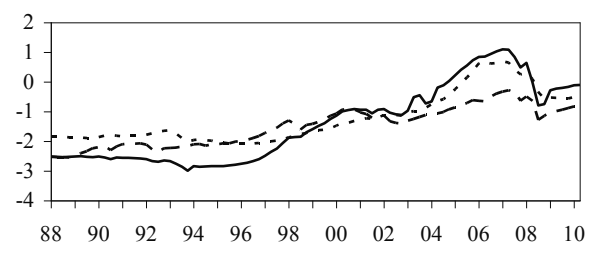

France

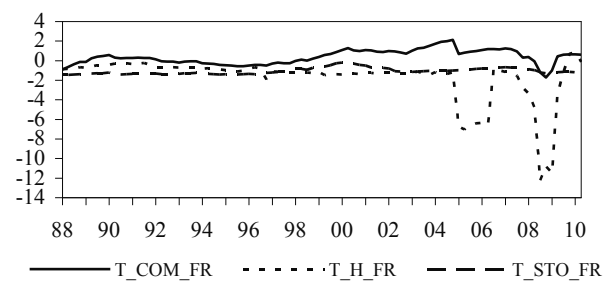

Italy

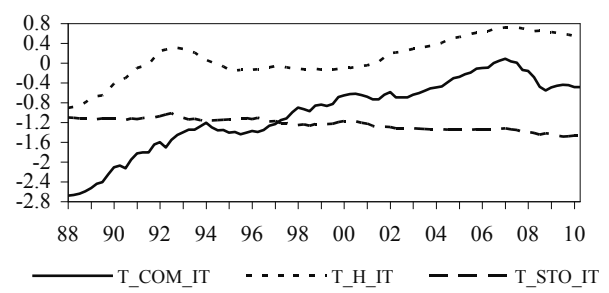

Germany

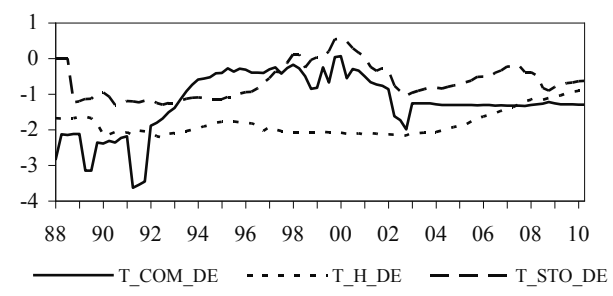

Spain

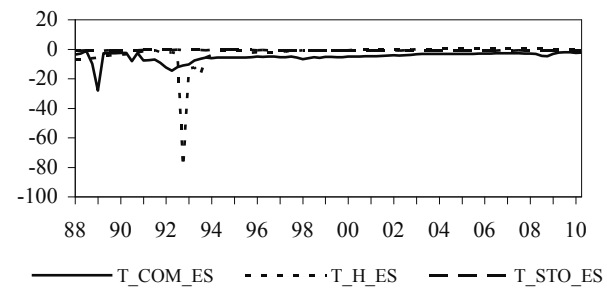

Ireland

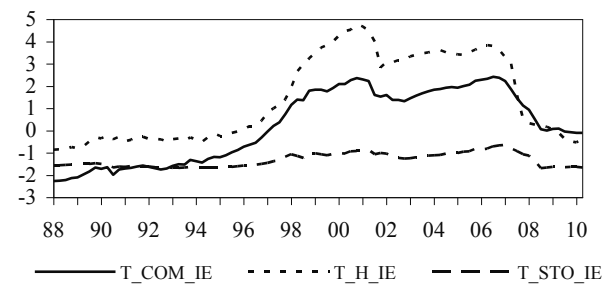

Japan

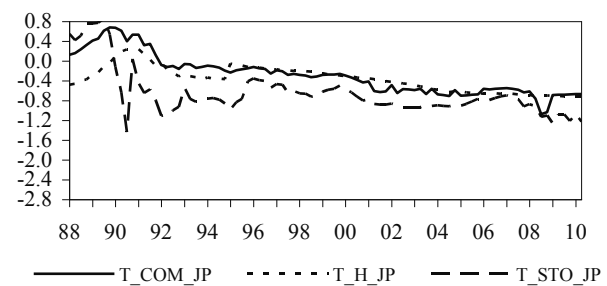


Netherlands

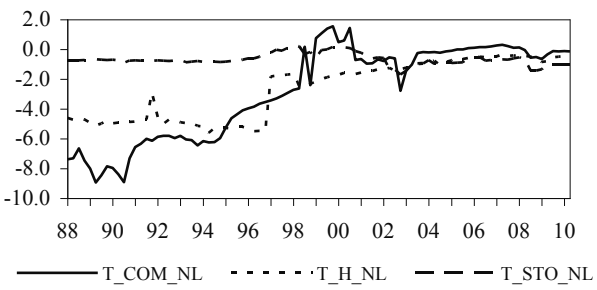

Norway

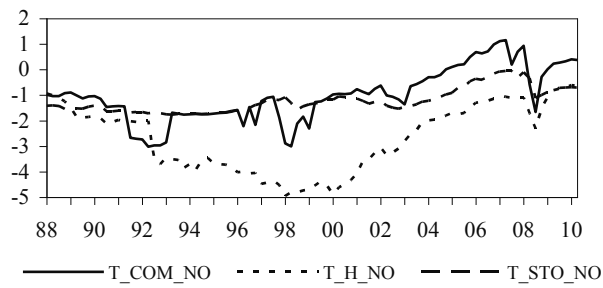

New Zealand

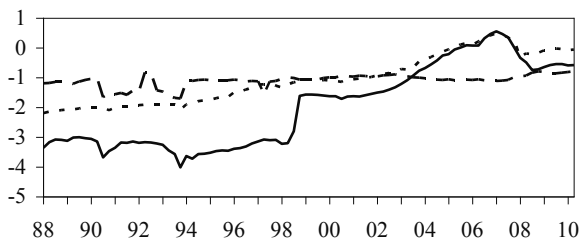

Sweden

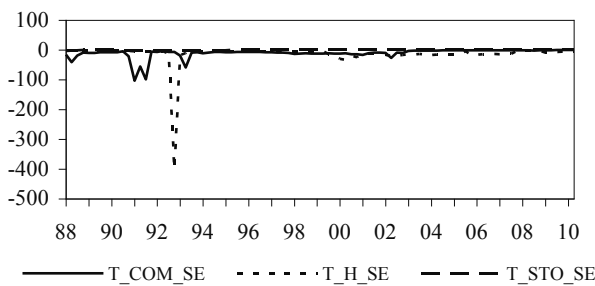

United Kingdom

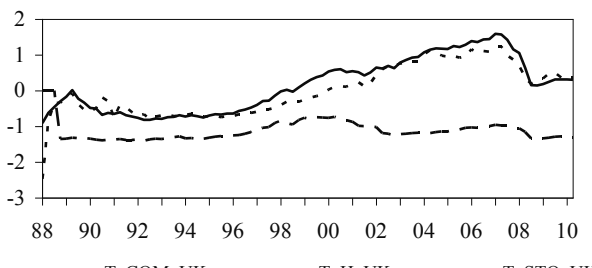

Fig. 2. Recursively determined t-statistic

Source: own research.

\section{Portugal}

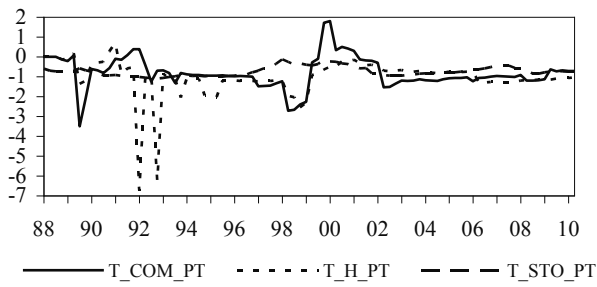

Euro area

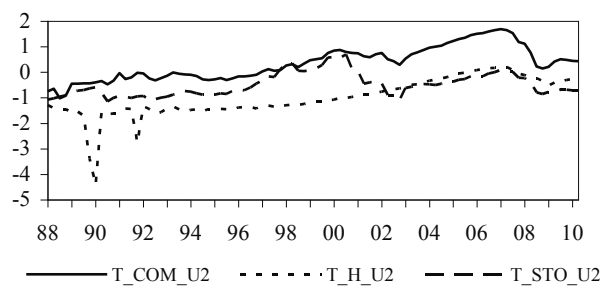

\section{United States}

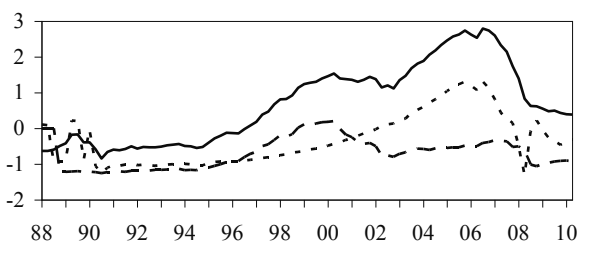


Table 2. Periods of exceeding the critical values

\begin{tabular}{|c|c|c|c|}
\hline Country & Real stock price & Real house price & Composite indicator \\
\hline Australia & - & $2001 \mathrm{Q} 1: 2010 \mathrm{Q} 2$ & $2001 \mathrm{Q} 1: 2010 \mathrm{Q} 2$ \\
\hline Canada & - & 2004 Q2 : 2008 Q2 & $\begin{array}{l}2005 \text { Q3 : } 2008 \text { Q3 } \\
2009 \text { Q1 : } 2010 \text { Q2 }\end{array}$ \\
\hline Denmark & - & 2006 Q1 : 2007 Q3 & $2005 \mathrm{Q} 4: 2008 \mathrm{Q} 2$ \\
\hline Euro area & 2000 Q3 : 2000 Q4 & - & $\begin{array}{l}1999 \mathrm{Q} 4: 2001 \mathrm{Q} 2 \\
2001 \mathrm{Q} 4: 2002 \mathrm{Q} 2 \\
2003 \mathrm{Q} 2: 2008 \mathrm{Q} 3\end{array}$ \\
\hline France & - & 2009 Q4 : 2010 Q2 & 1999 Q3 : 2007 Q4 \\
\hline Germany & - & - & - \\
\hline Ireland & - & 1997 Q3 : 2007 Q4 & 1997 Q4 : 2008 Q2 \\
\hline Italy & - & $2006 \mathrm{Q} 2: 2009 \mathrm{Q} 2$ & \\
\hline Japan & $\begin{array}{l}\text { 1986 Q4 : 1988 Q1 } \\
1988 \text { Q4 : 1989 Q4 }\end{array}$ & - & 1989 Q4 : 1990 Q2 \\
\hline The Netherlands & - & - & $\begin{array}{l}1999 \text { Q1 : } 2001 \text { Q1 } \\
2000 \text { Q3 : } 2000 \text { Q4 }\end{array}$ \\
\hline New Zealand & - & - & - \\
\hline Norway & - & - & $\begin{array}{l}2006 \mathrm{Q} 1: 2007 \mathrm{Q} 3 \\
2007 \mathrm{Q}: 2008 \mathrm{Q} 2 \\
\end{array}$ \\
\hline Portugal & - & - & 1999 Q4 : 2001 Q2 \\
\hline Spain & - & - & - \\
\hline Sweden & 1999 Q3 : 2000 Q3 & - & - \\
\hline Switzerland & - & 1988 Q1 : 1988 Q2 & - \\
\hline United Kingdom & - & 2002 Q3 : 2008 Q2 & 2002 Q1 : 2008 Q3 \\
\hline United States & - & 2004 Q2 : 2007 Q2 & 1997 Q4 : 2008 Q4 \\
\hline
\end{tabular}

Source: own calculations.

This study confirms results of a former analysis of Gerdesmeier, Reimers and Roffia ${ }^{31}$. They use of the same country sample but the shorter period 1969 Q1 - 2008 Q3 and carry out univariate and multivariate panel tests to find evidence of bubbles in the stock market. Univariate tests clearly reject the non-bubble hypothesis pointing towards the fact that there have been for some countries and sometimes over protracted periods from the path implied by the fundamentals. However, the results based on cointegration tests provide clear evidence against the existence of a bubble. It is noticeable, therefore, that the results stemming from the unit root tests and the cointegration tests point to different directions, thus requiring further investigation on the basis of other techniques and methodologies. 


\section{Conclusions}

Large swings in asset prices, interest rates and economic activity in a variety of countries over the past several years have brought new attention to the behaviour of asset markets. Generally speaking, it is a well established fact that distinguishing the nature of the sources of asset price movements - and, therefore, if the eventual bursting of such bubbles is likely to be destabilising for the financial system and the real economy - in real time is an extremely difficult task, as estimates of the equilibrium value of asset prices are usually surrounded by a high degree of uncertainty.

This paper contributes to the related literature by applying a new bubble test checking the explosiveness of asset prices, especially real stock prices, real house prices and a combination of these prices. The answer to this question is of utmost relevance for a number of areas, not least for either financial market participants or for central banks aiming at pursuing a policy of "leaning against the wind". In this study, we make use of a sample of 17 OECD industrialised countries and the euro area over the period 1969 Q1 - 2010 Q2 and carry out recursive unit root to determine the beginning and the end of a period of bubble behaviour. The new test procedure finds evidence for rejecting the non-bubble hypothesis. Particularly the composite indicator includes hints of bubble situations before the actual financial crisis.

\section{Notes}

1 Brunnenmeier (2008).

2 See, for instance, Gurkaynak (2008).

3 Diba, Grossman $(1987,1988)$.

4 Gerdesmeier, Reimers, Roffia (2011).

5 Phillips, Yu, (2010).

6 See Campbell, Lo, MacKinlay (1997, Chapter 1).

7 See, for instance, Balke, Wohar (2001), as well as Campbell, Lo, MacKinlay (1997, Chapter 7).

8 See, for instance, Sharpe, Gordon, Bailey (1999, Chapter 17).

9 See Campbell, Lo, MacKinlay (1997, Chapter 1).

${ }^{10}$ See, for instance, ECB, (2002).

11 See Froot, Obstfeld (1991).

12 See ECB (2003).

13 Filardo (2004).

14 Kindleberger (1978).

15 Shiller (2005).

16 Simon (2003).

17 Brunnermeier (2008). 
18 Grantham (2008).

${ }^{19}$ Froot, Obstfeld (1991).

${ }^{20}$ Phillips, Yu (2010).

${ }^{21}$ Ibidem.

22 Ibidem.

${ }^{23}$ Ibidem.

24 This approach is a standard practice in the literature on currency crises, whereby the crisis indicators are usually obtained by statistical analysis of the exchange rate and official international reserve series. The weighting scheme used between the two series is generally inversely proportional to their conditional variance. When the pressure indicator goes above a certain threshold, it is deemed that there is a currency crisis. The threshold used is generally two or three standard deviations above the mean. The greater the number of the standard deviations, the smaller the number of identified crises.

${ }^{25}$ An alternative weighting scheme is the one applied by the Bank for International Settlements, which combines equity and property prices by their respective share of private wealth.

${ }^{26}$ See Gerdesmeier, Reimers, Roffia (2010), in particular Annex 3.

${ }^{27}$ For a few variables in some counties the starting point may be slightly later (see the same Annex 3 of the paper mentioned above for more detail on the starting date for each series for each country).

${ }^{28} \mathrm{Ng}$, Perron (2001).

29 MacKinnon (1996).

${ }^{30}$ Phillips, Yu (2010).

${ }^{31}$ Gerdesmeier, Reimers. Roffia (2011).

\section{References}

Balke, N.S. \& Wohar, M.E. (2001). Explaining stock price movements: is there a case for fundamentals. Federal Reserve Bank of Dallas Economic and Financial Review, 3rd Quarter, $22-34$.

Brunnenmeier, M.K. (2008). Bubbles. In S.N. Durlauf \& L.E. Bluem (Eds.), New Palgrave Dictionary of Economics, $2^{\text {nd }}$, London: Macmillan.

Campbell, J.Y., Lo, A.W. \& MacKinlay, A.C. (1997). The econometrics of financial markets. Princeton University Press, Princeton.

Caporale, G.M. and Gil-Alana, L.A. (2004). Fractional cointegration and tests of present value models. Review of Financial Economics, 13, 245-258.

Diba, B.T. \& Grossman, H. (1987). On the inception of rational bubbles. Quarterly Journal of Economics, 87, 697-700.

Diba, B. \& Grossman, H. (1988). The theory of rational bubbles in stock prices. The Economic Journal, 98, 746-754.

European Central Bank (2002). The Stock Market and Monetary Policy, ECB Monthly Bulletin, February 2002, 39-52. 
European Central Bank (2003). Issues raised at the ECB Workshop on "Asset prices and monetary policy”, by C. Detken, K. Masuch \& F. Smets (European Central Bank).

Filardo, A. (2004). Monetary policy and asset price bubbles: calibrating the monetary policy trade-offs. BIS Working Paper, 155.

Froot, K.A. \& Obstfeld, M. (1991). Intrinsic bubbles: the case of stock prices. American Economic Review, 81, 1189-1214.

Grantham, J. (2008). Reaping the whirlwind. Quarterly Letter part 1, October, GMO Boston.

Gerdesmeier, D., Reimers, H.-E. \& Roffia, B. (2010). Asset price misalignments and the role of money and credit. International Finance, 13(3), 377-407.

Gerdesmeier, D., Reimers, H.-E. \& Roffia, B. (2011). Testing for the existence of a bubble in the stock market. In: A. Michler \& T. Polleit (Eds.), Financial crisis, forthcoming.

Gurkaynak, R.S. (2008). Econometric tests of asset price bubbles. Taking stock. Journal of Economic Surveys, 22, 166-186.

Kindleberger, C. (1978). Manias, panics and crashes: a history of financial crises. New York: John Wiley.

MacKinnon, J.G. (1996). Numerical distribution functions for unit root and cointegration tests. Journal of Applied Econometrics, 11, 601-618.

Ng, S. \& Perron, P. (2001). Lag length selection and the construction of unit root tests with good size and power. Econometrica, 69, 1519-1554.

Phillips, P.B.C. \& Yu, J. (2010). Dating the timeline of financial bubbles during the subprime crisis. Cowles Foundation Discussion Paper, 1770, Yale University.

Sharpe, W.F.; Gordon, J.A. \& Bailey, J.W. (1999). Investments. New Jersey: Prentice-Hall International, sixth edition.

Shiller, R. (2005). Irrational exuberance. New York: Broadway Books, 2nd edition.

Simon, J. (2003). Three Australian asset-price bubbles. Paper presented at the Conference in Australia. 